\section{УдК 330.3:330.8}

\section{JEL classification: B2, 010, 030, 047}

\section{Юлія ЄРЕШКО}

кандидат економічних наук, доцент, доцент,

кафедра теоретичної та прикладної економіки,

Національний технічний університет

України «Київський політехнічний інститут», Україна

E-mail: julia.jereshko@gmail.com https://orcid.org/0000-0002-9161-8820 https://publons.com/researcher/AAK-27512020/

\section{(C) Юлія Єрешко, 2021}

Отримано: 01.05.2021 p.

Прорецензовано: 15.05.2021 p.

Рекомендовано до друку: 26.05.2021 р. Опубліковано: 26.05.2021 р.

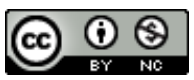

Ця стаття розповсюджується на умовах ліцензії Creative Commons AttributionNonCommercial 4. 0, яка дозволяє необмежене повторне використання, розповсюдження та відтворення на будь-якому носії, за умови правильного цитування оригінальної роботи.
Юлія Єрешко (Україна)

\section{П'ЯТИВУЗЛОВА СИНЕРГІЯ ЯК ОПТИМАЛЬНА ІННОВАЦІЙНА МОДЕЛЬ}

\section{АнотАцІя}

Вступ. Проблематика осягнення закономірностей і факторів економічного зростання знаходить своє відображення в доробку науковців, політиків, істориків і публіцистів від античності до сьогодення. Економічна система трансформується, разом з тим еволюціонуючи почасти випадковим чином, а кількісні зміни доволі часто і з долею вірогідності передують якісним. Системи такого типу характеризуються біфукарційним характером розвитку, тобто зміною якісної поведінки таких динамічних нерівноважних систем за незначної альтернації ї параметрів, точками біфуркації (переходу або поступу) $\epsilon$ економічні кризи, а рівноважний стан - це лише певний момент у їх русі і розвитку. Такий характер еволюції $€$ визначальним для всієї сукупності складних багатокомпонентних нелінійних систем, представлених багатопараметричною множиною динамічних систем нижчого порядку, до яких відносяться й економічні. Разом з тим, така типологізація автоматично означає логічну проблему віднайдення закономірностей їх руху і розвитку, зважаючи на складність передбачення реакції такого типу систем на вплив і зміну їх параметрів.

Метою статті $€$ обґрунтування оптимальної інноваційної моделі економіки на основі детермінації ключового фактору економічного розвитку.

Методологічною базою дослідження $\epsilon$ діалектичний аналіз, метод дослідження причинності явищ, детермінізм у вивчені систем, теоретикологічні узагальнення та гіпотези.

Результати. Здійснена характеристика економічних систем як складних, багатокомпонентних та хаотичних, тобто таких, що можуть бути детерміністичними і передбачуваними лише в теорії, пояснює стохастичний характер економічних закономірностей і логічну відсутність «універсального» рецепту розвитку, що доводить необхідність пошуку ендогенних факторів розвитку. На основі припущення про єдину природу розвитку і нерівномірності, визначено, що стрижнем інноваційного розвитку в сучасному світі стає інтелектуалізація економічних систем. Фактором же нерівномірності і одночасно розвитку, в сучасному розумінні, тобто розвитку інноваційного $\epsilon$ інтелектуальний капітал, що продукує інноваційний спалах, який за відповідного працюючого механізму перетворюється в рушій розвитку. Проведене дослідження теорій розвитку доводить необхідність ендогенізації «залишку Соллоу», адже припущення про екзогенну природу науковотехнічного розвитку, а отже і економічного зростання, не пояснює корінні причини нерівномірного розвитку окремих економік, а відтак, не пояснює ключового фактору розвитку. Безумовно, загальна траєкторія глобального розвитку задається екзогенно, водночас, вона починається з ендогенного інноваційного спалаху, який перетворюється на інноваційний потік і утворює технологічну базу, що приймається рештою економічних систем. Контрадикція неокласичної парадигми та інституціоналізму $€$ суто номінальною, адже встановлення правил і директив інституціями може виходити із «ratio» i конвергенція економічних агентів - інститутів, або їх синергія може забезпечувати рекурсивну директивність їх системі, тобто економічній системі в цілому, а «нераціональні» правила будуть органічно відкалібровані в результаті цієї взаємодії, одночасно, наявність правил надасть хаотичній багатокомпонентній системі деякої додаткової детермінованості. На цій основі запропоновано п'ятивузлову синергію в якості інноваційної моделі розвитку економіки, яка враховує всю сукупність взаємодій між економічними агентами в їх спільному розвитку і конфлікті, визначаючи оптимальну траєкторію загального сталого економічного зростання системи в цілому.

Єрешко Ю. П'ятивузлова синергія як оптимальна інноваційна модель. Економічний аналіз. 2021. Том 31. № 2. С. 25-33.

\section{DOI: https://doi.org/10.35774/econa2021.02.025}

Ключові слова: сталий розвиток; економічне зростання; залишок Соллоу; інтелектуальний капітал; теорія ендогенного зростання; неокласична парадигма; інституціоналізм. 


\section{UDC 330.3:330.8}

\section{JEL classification: B2, 010, 030, 047}

\section{Julia YERESHKO}

PhD in Economics, Associate Professor, Department of Theoretical and Applied Economics,

National Technical University of Ukraine "Kyiv Polytechnic Institute", Ukraine E-mail: julia.jereshko@gmail.com https://orcid.org/0000-0002-9161-8820 https://publons.com/researcher/AAK-27512020/

(C) Julia Yereshko, 2021

\section{Received: 01.05.2021}

Revised: 15.05.2021

Accepted: 26.05.2021

Online publication date: 26.05 .2021

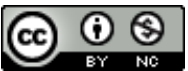

This is an Open Access article, distributed under the terms of the Creative Commons AttributionNonCommercial 4. 0 license, which permits unrestricted re-use, distribution, and reproduction in any medium, provided the original work is properly cited.

\section{Julia Yereshko (Ukraine)}

\section{FIVE-FOLD SYNERGY AS AN OPTIMAL INNOVATIVE MODEL}

\section{ABSTRACT}

Introduction. The issue of understanding the patterns and factors of economic growth is reflected in the work of scientists, politicians, historians and publicists from antiquity to the present. The economic system is transforming, at the same time evolving partly randomly, and quantitative changes often precede qualitative ones. Systems of this type are characterized by the bifucarial nature of development, i.e. a change in the qualitative behaviour of such dynamic nonequilibrium systems with a slight alternative to their parameters, bifurcation points (transition or progress) of which are the economic crises, and the equilibrium state is only a certain moment in their movement and development. This nature of evolution is decisive for the whole set of complex multicomponent nonlinear systems, represented by a multiparameter set of dynamic systems of lower order, which include economic ones. However, this typology automatically means a logical problem of finding patterns of their movement and development, given the difficulty of predicting the reaction of this type of system to the impact and change of their parameters.

The aim of the article is to substantiate the optimal innovative model of the economy based on the determination of a key factor of economic development.

The methodological basis of the research is dialectical analysis, the method of studying the causality of phenomena, determinism in the study of systems, theoretical and logical generalizations and hypotheses.

Results. The characterization of economic systems as complex, multicomponent and chaotic, i.e. those that can be deterministic and predictable only in theory, explains the stochastic nature of economic laws and the logical absence of a "universal" recipe for development, which proves the need to find endogenous factors. Based on the assumption of a unified nature of development and unevenness, it is determined that the core of innovative development in the modern world is the intellectualization of economic systems. The factor of unevenness and development, at the same time, in the modern sense, development innovative that is, is the intellectual capital, which produces an innovative flash, which with the appropriate working mechanism becomes the driving force of development. The study of development theories proves the need to endogenize the "Sollow residual", because the assumption of the exogenous nature of scientific and technological development, and hence economic growth, does not explain the root causes of the uneven development of individual economies, and therefore does not explain the key development factor. Naturally, the general trajectory of global development is set exogenously, at the same time, it begins with an endogenous innovation outbreak, which turns into an innovation flow and forms the technological base adopted by the rest of economic systems. The contradiction of the neoclassical paradigm and institutionalism is purely nominal, because the establishment of rules and directives by institutions can be based on "ratio" and convergence of economic agents - institutions, or their synergy can provide recursive directiveness to the system, the economic system as a whole, that is, and "irrational" rules will be organically calibrated as a result of this interaction, at the same time, the presence of rules will give the chaotic multicomponent system some additional determinism. Thus, a five-fold synergy is proposed as an innovative model of economic development, which takes into account the whole set of interactions between economic agents in their joint development and conflict, determining the optimal trajectory of overall sustainable economic growth.

Yereshko, J. (2021). Five-fold synergy as an optimal innovative model. Economic analysis, 31 (2), 25-33.

DOI: https://doi.org/10.35774/econa2021.02.025

Keywords: sustainable development; economic growth; Sollow residual; intellectual capital; theory of endogenous growth; neoclassical paradigm; institutionalism. 


\section{Вступ}

Проблематика осягнення закономірностей і факторів економічного зростання знаходить своє відображення в доробку науковців, політиків, істориків і публіцистів від античності до сьогодення. Кожна економічна епоха характеризується своїми особливостями, закономірностями і характером розвитку, передумовами поступу і прогресивного перетворення до кожної наступної за переконанням Маркса $є$ трансформація виробничих факторів. Економічна система трансформується, разом 3 тим еволюціонуючи почасти випадковим чином, а кількісні зміни доволі часто і з долею вірогідності передують якісним. Останні результують у революційну перебудову економічної системи, часто як відповідь на деструкцію, опосередковуючи перехід у новий стан, або виникнення принципово нової системи. Системи такого типу характеризуються біфукарційним характером розвитку, тобто зміною якісної поведінки таких динамічних нерівноважних систем за незначної альтернації їх параметрів, точками біфуркації (переходу або поступу) $\epsilon$ економічні кризи, а рівноважний стан - це лише певний момент у їх русі і розвитку. Такий характер еволюції $\epsilon$ визначальним для всієї сукупності складних багатокомпонентних нелінійних систем, представлених багатопараметричною множиною динамічних систем нижчого порядку, до яких відносяться й економічні. Разом 3 тим, така типологізація автоматично означає логічну проблему віднайдення закономірностей їх руху i розвитку, зважаючи на складність передбачення реакції такого типу систем на вплив і зміну їх параметрів.

\section{Мета статті}

Метою статті $\epsilon$ обґрунтування оптимальної інноваційної моделі економіки на основі детермінації ключового фактору економічного розвитку.

Методологічною базою дослідження $\epsilon$ діалектичний аналіз, метод дослідження причинності явищ, детермінізм у вивчені систем, теоретико-логічні узагальнення та гіпотези.

\section{Виклад основного матеріалу дослідження}

Вивчення систем та формування знань i теоретичних узагальнень про них В науці здійснюється 3 використанням принципу детермінізму, тобто припущення про те, що знання про поточний стан системи та законів і закономірностей розвитку опосередковує можливість припущення про майбутню поведінку цієї системи. Разом з тим, в природі існує ряд систем, в яких результат конкретної дії суттєво залежить від порівняно незначного керуючого впливу і майбутня поведінка таких систем $\epsilon$ непередбачуваною. В таких системах незначні зміни вихідних умов можуть непрогнозовано призводити до незначних змін на виході або до радикальних, а подекуди, не впливати на систему взагалі. Економічні системи важко піддаються детермінізму i не належать до класичних Ньютонівських систем, а отже, вони $€$ набагато більш чутливими до визначення вихідних умов управлінського впливу.

Звідси, зважаючи на складність, багатофакторність економічних систем, причиннонаслідкові зв'язки економічного зростання не підпадають, на перший погляд, під детермінізм в сенсі обґрунтування динамічних закономірностей їх еволюції які $б$ чітко виявляли кореляцію між усвідомленням конкретного стану економічної системи і іï стану поточного (майбутнього) в результаті впливу або зміни параметрів. Водночас, існує проблема знання про систему, вірніше, відсутності достовірної та повної інформації про неї. Оскільки, ведучи мову про вихідний їі стан, ми автоматично маємо на увазі визначення вхідних параметрів, фактично їх вимірювання. Кожне вимірювання в реальному житті містить певну стохастичну помилку, деяку неточність, відхилення від фактичної величини цих параметрів. Отже, достовірна оцінка реального поточного стану системи видається неможливою. Одночасно, для хаотичних динамічних систем існування можливості теоретичного передбачення поведінки i майбутнього стану $€$ можливим лише у випадку визначення вихідних параметрів 3 абсолютною точністю, без права на похибку.

Водночас, характеристика хаотичності автоматично не виключає застосування детермінізму, радше означає наявність деякої розбіжності між теоретичним усвідомленням системи і їі закономірностей та реальним ії втіленням. Ця розбіжність означає те, що система може бути детерміністичною і передбачуваною лише в теорії. Саме тому, економічні закономірності носять деякий стохастичний характер, і визначення як вхідних, так і вихідних параметрів системи є можливим лише 3 долею вірогідності, тенденції розвитку можуть виявлятись і оцінюватись переважно постфактум і їx екстраполяція на, здавалося б, аналогічні економічні системи доволі часто не приносить очікуваного результату.

Тобто, вибір відомої дієвої системи розвитку не означає автоматично аналогічних результатів для кожної окремої економічної системи. Про відсутність такого «універсального рецепту розвитку» закон нерівномірності економічного зростання. Тривалий час нерівномірність розвитку 
вважалась природньою його характеристикою i основним його рушійним фактором. Разом з тим, можливо саме в деоб'єктивізації нерівномірності розвитку лежить ключ до розуміння його наріжних закономірностей.

Найчастіше її розуміють як різницю в масштабах і швидкості розвитку окремих секторів економіки або окремих національних економік, частин світової господарської системи, що виявляється в різних темпах приросту ВВП і динаміці продуктивності праці окремих економік [1]. Водночас, хоча відхилення даних показників і дають наочність нерівномірності розвитку, першопричина ії залишається не дослідженою. I, для кожної економічної епохи ця першопричина відрізняється, як і першопричина економічного зростання. Таким чином, логічним є припущення про єдину природу розвитку і нерівномірності, тобто єдину причину обох. Якщо переважну більшість економічних епох нерівномірність розвитку пояснювалась сукупністю ендогенних факторів національних економік, а саме: географічним і гео-політичним положенням, природніми ресурсами, кліматичними умовами, нерівномірністю прогресу і розвитку окремих продуктивних сил тощо, то за сучасних умов науково-технічного прогресу і глобалізації, вона зумовлена переважно нерівномірністю продукування інновацій, наукових і технічних розробок і нерівномірністю їх освоєння. Сьогодні, природнє і політичне становище країни відіграє вторинну роль у їі розвитку і лідери інновацій стають лідерами економічними.

За даними індексу Глобальної Конкурентоспроможності Всесвітнього Економічного Форуму, першу десятку лідерів складають: Сингапур (індекс - 84,8), Сполучені Штати Америки $(83,7)$, Гонконг $(83,1)$, Нідерланди $(82,4)$, Швейцарія $(82,3)$, Японія(82,3), Німеччина $(81,8)$, Швеція $(81,2)$, Сполучене Королівство $(81,2)$, Данія $(81,2)$, Україна ж займає 85-те місце серед 141 країн, що входять до рейтингування із індексом 57,0 [2]. Причому, згідно Звіту, що декларує національну конкурентоспроможність як «сукупність інститутів, політики та факторів, що визначають рівень продуктивності праці», одним 3 показників найбільшої ваги, серед сукупності використовуваних для обрахування рейтингу, $€$ "фактори інновацій та розвитку», таким чином, аналіз показників діяльності даних економік у цій сфері дозволяє зробити висновок про результати впливу інтелектуалізації економіки на ії конкурентоспроможність. Отже, за даними Індексу Глобальної Інноваційності, перша десятка загального рейтингу виглядає так: Швейцарія (індекс - 66,08), Швеція $(62,47)$, Сполучені Штати Америки $(60,56)$, Сполучене Королівство $(59,78)$,
Нідерланди $(58,76)$, Данія $(57,53)$, Фінляндія $(57,02)$, Сінгапур $(56,61)$, Німеччина $(56,55)$, Корея $(56,11)$, Україна посіла 44 позицію зі 131 із результатом у 36,32 [3]. Звідси, очевидною $\epsilon$ кореляція, за деякими виключеннями, позицій лідерів обох рейтингів, що дає підставу припустити, що конкурентоспроможність економіки країни визначається саме науково-технічним розвитком та обсягом вкладень у інтелектуальний капітал.

Тобто, стрижнем інноваційного розвитку в сучасному світі стає інтелектуалізація економічних систем. Фактором же нерівномірності і одночасно розвитку, в сучасному розумінні, тобто розвитку інноваційного $\epsilon$ інтелектуальний капітал, що продукує інноваційний спалах, який за відповідного працюючого механізму перетворюється в рушій розвитку.

Історично акумуляція людського та інтелектуального капіталу за деяких сприятливих умов результує у технологічному прориві. Досягнення концентрації обох форм капіталу порогового значення викликає інноваційний спалах - появу нових технологій і розробок, впровадження яких, а також наступні удосконалення i доопрацювання формують технологічну базу, яка в свою чергу, стає основою подальшого поступу технологій, появи широкого спектру нових продуктів і процесних інновацій, формуючи тим самим інноваційний потік. Стійкість такого інноваційного потоку визначається попитом на інновації i, коли за умови, що його значення випереджає інтенсивність їх продукування, потік підсилюється. В протилежній ситуації - затухає. Тобто, працездатність інноваційної моделі розвитку напряму залежить від «інноваційного попиту» i, що цікаво, агенти продукування інновацій і агенти їх надбання переважно збігаються. Разом з тим, вихідні параметри системи подекуди вимагають контрольованого інноваційного попиту для надання поштовху інноваційному потоку, його спрямування у власну економіку, тобто перетворення його на рушійний фактор ендогенної моделі розвитку. Адже, у випадку відсутності достатнього обсягу ефективного попиту з боку економічних агентів, можливими стають два наступні сценарії: 1) інноваційний спалах затухає не перетворившись на інноваційних потік; 2) інноваційний спалах привласнюється екзогенними економічними агентами або системами, не створюючи фактору зростання системі внутрішній. Обидва сценарії, на жаль, притаманні вітчизняній економічній системі і опосередковують специфічність її розвитку.

Важливість забезпечення внутрішнього ефективного попиту на інновації знаходить своє відображення у теоріях ендогенного економічного зростання, які, незважаючи на відносну новизну і 
деякий брак емпіричного доведення, набувають сьогодні все більшої популярності і поширення, оскільки їм властива ключова перевага перед теоріями неокласичними - спроба пояснити внутрішню природу сил і рушіїв технологічних змін в середині економічної системи, на противагу неокласичному припущенню про їх екзогенний характер. Так, запропонована Соллоу та Своном в середині 50-х рр XX ст. модель економічного зростання стала в своєму роді революційною, змінивши погляди економістів на закономірності еволюції економічних систем. Разом з тим, вона має вагомий недолік - припущення про екзогенну природу науково-технічного розвитку, а отже i економічного зростання, що не пояснює корінні причини нерівномірного розвитку окремих економік, а відтак, головна її теза про залежність приросту ВВП від темпів науково-технічного прогресу не пояснює ключового фактору розвитку, тобто, може слугувати лише відправною точкою подальшого дослідження причин і закономірностей економічного зростання. Таким чином, опосередковуючи потребу в ендогенізації науковотехнічного прогресу в спробі вирішення фундаментальних питань теорії економічного зростання.

Очевидна, на перший погляд, складність задоволення цій потребі виходить із номінальної контрадикції неокласичної парадигми та інституціоналізму: «Невидима рука» Сміта здригається під впливом інституцій», тобто за логікою дослідників і теоретиків останній автоматично дорівнює зарегульованості [4]. Ідея раціоналістичних вибору і поведінки економічних агентів протиставляється «нав'язуваним» інституціями формальним і неформальним правилам, що, здається, виключають свободу лібералістичного економічного "ratio», замінюючи його на директивне інституційне «mustum». Однак, наявність правил не означає виключення свободи вибору, як і наявність економічного мотиву у максимально можливому задоволенні потреб не означає раціональної поведінки і, одночасно, інституціоналізм не дорівнює тоталітаризму.

Відповідно постає питання можливості розширення, чи, вірніше, наповнення неокласичної парадигми інституціональним змістом. Якщо припустити, що встановлення правил і директив інституціями може виходити із «ratio» i конвергенція економічних агентів - інститутів, або їх синергія може забезпечувати рекурсивну директивність їх системі, тобто економічній системі в цілому, то «нераціональні» правила будуть органічно відкалібровані в результаті цієї взаємодії, одночасно, наявність правил надасть хаотичній багатокомпонентній системі деякої додаткової детермінованості. Дане припущення можна обґрунтувати системою соціуму 3 правилами, нормами та законами, які, справедливо, дещо обмежують дії членів суспільства, одночасно не виключаючи свободи вибору. Тобто, наявність правил в суспільстві впливає на формування у його членів розуміння "ratio», а правила, що віджили себе з тих чи інших причин елімінуються або коригуються відповідного до поточного щабля розвитку соціальної системи.

До того ж, правила і норми соціуму впливають на людину економічну, репрезентовану чи то споживачем, чи працівником, чи підприємцем, або чиновником. Тобто, теоретично, за чистою неокласичною логікою вони мають виключати "Laissez-faire», так само i наявність законів і нормативних актів, що забезпечують дотримання прав і свободи, приватної власності - вони $\epsilon$ наріжними основами лібералізму і задоволення умовам реалізації агентами їх економічної волі. Описаний вище ефективний інноваційний попит логічно має бути раціональним рішенням економічних агентів, що виходять із максимізації вигоди, водночас, за відсутності адекватних фінансових та інших ресурсів в умовах вільного ринку, інноваційний потік буде привласнений найсильнішим i не обов'язково результує у економічне зростання.

На наш погляд, до технологічного розвитку, який сьогодні $\epsilon$ об'єктивною основою розвитку економічно належить ставитись дещо меркантелістично - плекаючи інновації всередині економіки, не дозволяючи органічній модернізації перетворитись на неорганічну. Особливо справедливим такий підхід $€$ для вітчизняної економіки, оскільки, через спірну ефективність інноваційної моделі розвитку і константу бідність, продукти розуму, інтелектуальний потенціал і знання нації переважно привласнюються i втілюються на благо іноземців. Україна, по суті, знаходиться у пастці розвитку не маючи можливості привласнювати на свою користь результати його ключового ресурсу. Однією 3 причин такого становища $\epsilon$ обґрунтовані попередньо аберації сталого розвитку, зокрема у випадку формування адекватної інноваційної моделі, - політизація, гіпертрофування та гіперборлізація. Останні нівелюють органічну рекурсивну директивність економічної системи переважуючи роль і значення деяких інституцій над рештою.

Аналогічно протиставляються й екзогенні та ендогенні теорії зростання 3 автоматичним припущенням про, відповідно, внутрішню чи зовнішню природу науково-технічного прогресу, що забезпечує економічне зростання. Припускаючи про екзогенну природу розвитку техніки і технологій, відкритим залишається питання про 
причини економічної нерівномірності окремих економік. Дійсно, глобалізація і інформаційна революція стирають кордони і межі в трансферті знань і технологій, і технологічний розвиток $\epsilon$ процесом всезагальним, водночас, продукти органічної модернізації, як і її наслідки надають відповідним економікам переваги. Разом з тим, як уже наголошено вище, початковий «майновий стан» країни відіграє не останнього значення у результуючому типі модернізації. Тобто, наявність необхідної кількості ресурсів сама собою не забезпечує інноваційного розвитку. Звідси, визначення фактору економічного зростання суто екзогенним чи ендогенним можна вважати дещо квапливим. Безумовно, загальна траєкторія глобального розвитку задається екзогенно, водночас, вона починається 3 ендогенного інноваційного спалаху, який перетворюється на інноваційний потік і утворює технологічну базу, що приймається рештою економічних систем. Крім того, в межах загальної глобальної траєкторії, заданої екзогенно, саме ендогенний фактор надає окремим економікам конкурентоспроможності і $\epsilon$ причиною і, одночасно, наслідком нерівномірності розвитку.

Перші успішні спроби поглиблення неокласичної теорії шляхом інкорпорування шумпетерівської "творчої руйнації» та еволюційного «природнього відбору» були здійснені П. Хьюїтом, Р. Лукасом, П. Ромером та Дж. Стігліцом [5]. Останньому, доречі, належить спроба визначити вартість «творчої руйнації» в якості критерія досягнутого економічного зростання. Вагомий внесок в теорію ендогенного розвитку належить П. Ромеру, який намагався знайти першоджерело зростання на мікроекономічному рівні, обґрунтувавши ефект масштабу інвестицій в НДДКР (R\&D) на максимізацію прибутку економічних агентів, що їх здійснюють [6].

Проблема ендогенізації «залишка Соллоу» дістала всебічного відображення у доробку Нідерландської школи Г. Сільверберґа, яка синтезувала неокласичну теорію зростання не тільки з парадигмою Шумпетера, але і теорією техніко-економічних моделей та довгих хвиль Кондратьєва в спробі зосередження саме на першопричині нерівномірності економічного зростання [7]. Модифікована модель Соллоу на основі технологічних зсувів та підбору нелінійних варіантів функції Кобба-Дугласа враховуючи процес дифузії технологій та їх заміщення у фазі «творчої руйнації», дозволяє опис процесів розвитку економіко-технологічних парадигм від інноваційного спалаху до затухання інноваційного потоку. Разом з тим, представники даної школи приймали неокласичну константність темпу технологічних змін, вважаючи проривні впливи науково-технічного прогресу екзогенними. До того ж, описана модель не враховує ролі інституцій і інноваційного попиту на формування та використання інноваційного потоку.

Вважаємо, що технологічний прорив може мати як екзогенний, так і ендогенний характер, водночас, саме останній забезпечує економічній системі найбільшої конкурентоспроможності і формує засади сталого економічного розвитку, оскільки, по-перше, забезпечує позицію лідера інновацій, по-друге, виходить із специфічних вихідних параметрів системи і специфічних ії потреб, тобто не потребує «прилаштування» неорганічної модернізації 3 іншої «успішної економіки». Ендогенні фактори розвитку $\epsilon$ природніми і компліментарними кожній економічній системі, забезпечуючи оптимальне зростання.

Теорія ендогенного розвитку, хоча і з браком емпіричного доведення, пропонує свіжий погляд на рушії економічного зростання, а саме: інтелектуальний капітал, людський капітал, інновації, науково-технічну діяльність тощо, що опосередковує можливість і доцільність контрольованого впливу на систему. Водночас, такий вплив має бути обережним і виходити не із монополії держави або ринку, а бути органічним результатом взаємодії сукупності, синергії «агентів впливу», обгрунтованих нами попередньо в якості надбудови запропонованої у [8] моделі сталого економічного розвитку: держави, підприємств, університетів та ринків. Така система забезпечує рекурсивний контроль кожної суб'єктної компоненти виключаючи директивний характер впливу, регламентуючи там самим причиннонаслідковий «партнерський» взаємозалежний розвиток. Схожим за логікою $€$ конструкт моделі стратегічних інноваційних мереж або, так званої, «потрійної спіралі» Г. Іцковиця, в основі якої лежить припущення автора про створення доданої вартості у ланцюжку інституцій, які $€$ носіями особливих специфічних знань [9].

Водночас, обрана науковцем методологія детермінації суб'єктних систем створення i привласнення знань в якості вузлів мережі почасти звужує площину дослідження розвитку до перетину трьох множин відносин, що провокує редукціонізм при вивченні економічної системи в цілому, зосереджуючись на описі взаємодії підприємницького сектору, держави і науковоосвітніх установ. Разом з тим, нові технології, що $€$ частиною інноваційного потоку проходять «витримку» ринком, і саме ринок забезпечує певний оптимум при визначенні напряму інноваційної діяльності. 3 іншого боку, тип ринку здійснює безпосередній вплив на інноваційний 
потік подекуди провокуючи затухання інноваційного спалаху або "технологічну пастку». Через ринок здійснюється і розподіл ресурсів, що визначає, з одного боку, конкурентну позицію компаній, секторів, економік, з іншого - формує інноваційний (модернізаційний) мотив. Саме ринок визначає вартість інтелектуального капіталу і саме на ринку проявляється його вартісноформуюча природа як економічного фактору. Таким чином, ринок $\epsilon$ беззаперечним агентом впливу на інноваційний процес і інноваційний розвиток. Разом $з$ тим, у моделі Іцковиця він як окремий інноваційний агент не присутній, хоча його вплив деякою мірою описаний. При цьому сукупність підприємств, університетів і держави не формують ринок загалом, лише деякі його спектральні часки сектори і специфічні ринки, що, знову ж таки, не дає повної наочності його представлення як елемента синергії, тим самим, провокуючи редукціонізм пізнання і спірність висновків.

На основі викладеного нами у [10], визначено ключову роль людини і людської свідомості як ресурсу розвитку, як носія знань і інтелектуального капіталу (невідокремленого від людини), або першочергового його носія (відокремленого). Людина за своєю економічною природою $\epsilon$ одночасно причиною виробничого процесу: в розрізі його направленості на задоволення суспільних та індивідуальних потреб, а також економічним фактором. Саме людина є джерелом технологічного розвитку і ключовим ресурсом розвитку інноваційного. Тому, людині, на нашу думку, належить роль центрального системоутворюючого елементу мережі розвитку. В загалі інноваційних моделей і моделі Іцковиця зокрема, людина не знаходить свого специфічного відображення.

Безумовною перевагою «потрійної спіралі» як аналітичної моделі опису множини інституційних механізмів, що утворюють національну інноваційну систему є спроба опису їх динаміки, разом з тим, вважаємо ії̈ не достатньо комплексною з точки зору охоплення всього динамізму економічного розвитку, опису сукупності інерційних траєкторій технологічного розвитку, що є визначальними для економічного зростання. Тому, на основі розробленої попередньо людиноцентричної парадигми сталого розвитку та викладеного вище пропонуємо п'ятивузлову синегрію - інноваційну модель економічного зростання (рис. 1), креативно-директивна взаємодія економічних агентів в умовах якої забезпечує досягнення сукупного компліментарного ефекту, порівняно більшого, за суму ефектів кожного економічного агента окремо та визначає спільну оптимальну траєкторію розвитку, не порушуючи неокласичних догм.

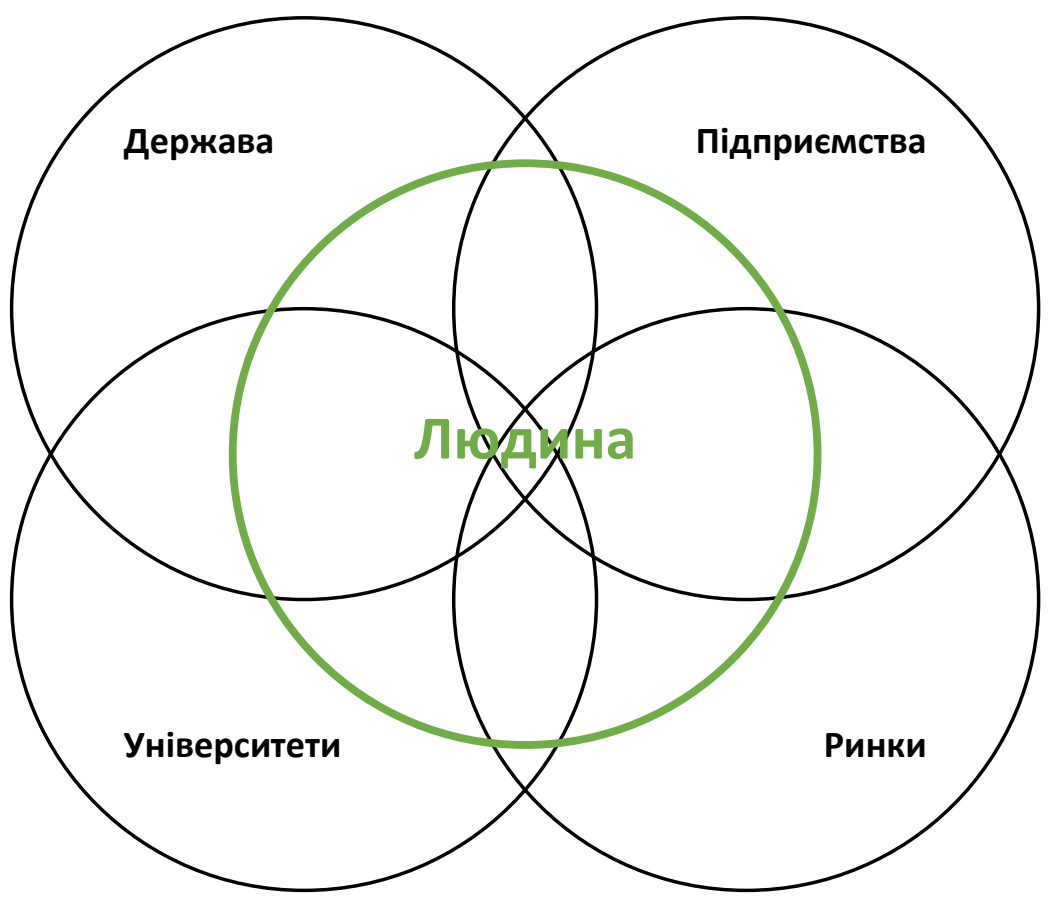

Рис. 1. П'ятивузлова синергія (розроблено автором)

Основною проблемою «потрійної спіралі» 3 деяким редукціонізмом детермінації інноваційних агентів $€$ підкреслювана її авторами випадковість компонент розвитку і його траєкторій [9], що виходить із випадковості винаходів, інноваційного спалаху та інноваційного попиту. А отже, 
автоматично означає неможливість результативного впливу на систему. На основі ж рекурсивної структури та інституційних компонент контролю, що охоплюють діяльність і потреби всієї множини інноваційних агентів видається можливим вибір оптимальної траєкторії розвитку або автоматичний, органічний перехід між альтернативними: розвиток кожного економічного агента впливає на агентів дотичних і множину агентів в цілому, провокуючи відповідний їх розвиток і в деяких точках (точках біфуркації) траєкторії розвитку агентів перетинаються, забезпечуючи тим самим перехід всієї системи 3 випадкової на оптимальну траєкторію розвитку. Таким чином, траєкторія сталого розвитку економіки в цілому формується саме природнім відбором технологій і винаходів, що забезпечується описаною інтеграцією економічних агентів у п'ятивузлову синергію. Причому, цей відбір відбувається виходячи із економічних потреб і мотивів кожного інтегрованого члена синергії.

Представлена п'ятикомпонентна синергія, на наш погляд, $є$ оптимальною, оскільки враховує всю сукупність взаємодій між економічними агентами в їх спільному розвитку і конфлікті, визначаючи оптимальну траєкторію загального сталого економічного зростання системи в цілому. Чотири вузли (кола) системи - держава, підприємства, ринки та університети (наукові установи, академії) $\epsilon$ фундаментальними елементами формування інноваційного спалаху та забезпечення інноваційного потоку і всіх їх об'єднує їх ключова роль участі у створенні і розвитку інтелектуального капіталу. Людина як його носій $€$ центральним зв'язуючим елементом синергії, без якого означені чотири кола розпадуться.

\section{Висновки та перспективи подальших розвідок}

Нерівномірність економічного і технологічного розвитку сьогодні стає, радше, не «логічною» його характеристикою, а мотивом. Мотивом до пошуку внутрішніх джерел росту і розвитку, насамперед розвитку науково-технічного, що можуть бути перетворені на «конкурентний захист» національної економіки в умовах глобалізації. Оскільки сьогодні не сировина і праця, а, головним чином, здатність створювати і використовувати ресурси знань стають домінантним фактором розвитку. Цим внутрішнім фактором $\epsilon$ інтелектуальний капітал, який забезпечуючи розвиток технологічний, стає наріжним у двох дотичних системах розвитку: економічному і суспільному.

Вихідні параметри нерівномірності відповідно можуть бути частково еліміновані, а частково перетворені на модернізаційний чи інноваційний мотив. Серед найінноваційніших і найбільш конкурентних економік ці вихідні параметри різні, i в сучасному світі можливості людського розуму відкривають нові переваги як для зростання, так і для конкуренції. Ресурсна чи енергетична перевага або особливе географічне положення сьогодні автоматично не означають лідерської позиції, для порівняння: нафтові Росія, Бразилія та Венесуела за рівнем життя доволі вагомо програють інтелектуалізованим інноваційним Нідерландам, Швеції та Сінгапуру. Основою успіху стає розум напротивагу традиційним фізичним і природнім частинам національного добробуту. І, цей розум, за вдалого спрямування, здатний перетворити фактори нерівності на фактори успіху.

Перспективою подальших досліджень $€$ логічно випливаюча із даного дослідження системна інтелектуальна трансформація моделі сталого розвитку вітчизняної економіки на основі запропонованої синергії економічних агентів.

\section{СПИСОК ВИКОРИСТАНИХ ДЖЕРЕЛ}

1. Kuznets S. (1955). Economic growth and income inequality. The American economic review, 45(1), 128.

2. Global Competitiveness Report 2019: How to end a lost decade of productivity growth https://www.weforum.org/reports/ how-to-end-a-decade-of-lostproductivity-growth

3. GII Annual Report 2020 https://www.wipo.int/edocs/pubdo cs/en/wipo_pub_gii_2020.pdf
4. Brožová D. (2015). Modern labour economics: the neoclassical paradigm with institutional content. Procedia Economics and Finance, 30, 50-56.

5. Pack H. (1994). Endogenous growth theory: intellectual appeal and empirical shortcomings. Journal of economic perspectives, 8(1), 55-72.

6. Romer P. M. (1994). The origins of endogenous growth. Journal of Economic perspectives, 8(1), 3-22.

7. Silverberg G., \& Soete L. (1994). The economics of growth and technical change. Edward Elgar Publishing.
8. Єрешко Ю. О. (2021). Актуалізація парадигми сталого розвитку 3 позиції ії людиноцентричності. Підприємни итво та інновації, 7.

9. Etzkowitz H. (2002). Incubation of incubators: innovation as a triple helix of university-industrygovernment networks. Science and Public Policy, 29(2), 115-128.

10. Єрешко Ю. О., \& Крейдич І. М. (2021). Ключовий інноваційний ресурс сталого розвитку. Економічний вісник Начіонального технічного університету України «Київський політехнічний інститут», (18). 


\section{REFERENCES}

1. Kuznets, S. (1955). Economic growth and income inequality. The American economic review, 45(1), 128.

2. Global Competitiveness Report 2019: How to end a lost decade of productivity growth https://www.weforum.org/reports/ how-to-end-a-decade-of-lostproductivity-growth.

3. GII Annual Report 2020 https://www.wipo.int/edocs/pubdo cs/en/wipo_pub_gii_2020.pdf.
4. Brožová, D. (2015). Modern labour economics: the neoclassical paradigm with institutional content. Procedia Economics and Finance, 30, 50-56.

5. Pack, H. (1994). Endogenous growth theory: intellectual appeal and empirical shortcomings. Journal of economic perspectives, 8(1), 55-72.

6. Romer, P. M. (1994). The origins of endogenous growth. Journal of Economic perspectives, 8(1), 3-22.

7. Silverberg, G., \& Soete, L. (1994). The economics of growth and technical change. Edward Elgar Publishing.
8. Yereshko, Yu. O. (2021) Aktualizatsia paradegmy staloho rozvytku z pozytaii ii liudynicentrychkosti. Pidpryjemnytst vo ta innovatsii, 7. [in Ukrainian].

9. Etzkowitz, H. (2002). Incubation of incubators: innovation as a triple helix of university-industrygovernment networks. Science and Public Policy, 29(2), 115-128.

10. Yereshko, Yu. O., \& Kreidych, I. M. (2021). Kliuchovyi innovatsijnyi resurs staloho rozvytku. Ekonomichnyi visnyk Natsionalnoho technichnoho universytetu Ukrainy "Kyivskyi politeknichnyi instytut», (18). [in Ukrainian]. 